\title{
Prognostic value of the distance of proximal resection margin in patients who have undergone curative gastric cancer surgery
}

HaengJin Ohe ${ }^{1,2}$, Woo Yong Lee ${ }^{1,2^{*}}$, Seong Woo Hong ${ }^{2}$, Yeo Goo Chang ${ }^{2}$ and Byungmoo Lee ${ }^{2}$

\begin{abstract}
Background: We conducted this retrospective study to analyze the relationship between the distance of the proximal resection margin (PRM) and the pattern of recurrence in patients with gastric cancer who underwent curative gastrectomy.

Methods: In our series, there were 774 patients who underwent curative gastrectomy for gastric adenocarcinoma. Thus, we classified our clinical series of patients into the distal gastrectomy group $(n=529)$ and the total gastrectomy group $(n=245)$. The clinical pathologic data and PRM distance were collected. Univariate and multivariate analyses were performed to evaluate association between PRM distance and locoregional recurrence.

Results: The mean distance of the PRM was $4.03 \mathrm{~cm}$ in the total gastrectomy group. The distance of the PRM had a significant correlation with advanced T-stage, advanced N-stage,vascular invasion,lymphatic invasion, neural invasion, histological undifferentiation, greater tumor size, and the upper third of the tumor location. On multivariate analysis, tumor recurrence showed only the independent prognostic factor $\mathrm{N}$-stage $(P<0.023)$. The mean distance of the PRM was $6.4 \mathrm{~cm}$ in the distal gastrectomy group. The distance of the PRM had a significant correlation with the advanced T-stage, advanced N-stage, younger age, vascular invasion, histological undifferentiation, greater tumor size, and the middle third of tumor location. On multivariate analysis, tumor recurrence showed three independent prognostic factors, $\mathrm{N}$-stage $(P<0.001)$, vascular invasion $(P=0.009)$, and lower third tumor location $(P=0.035)$. The total gastrectomy of locoregional recurrence was related to $\mathrm{N}$-stage $(P=0.039)$, and the distal gastrectomy of locoregional recurrence was related to T-stage $(P=0.021)$. Study on the disease-free survival, PRM distance, and locoregional recurrence was not statistically relevant in both the total and distal gastrectomy group $(P=0.565$ and $P=0.584$, respectively).
\end{abstract}

Conclusions: Our results indicate that a sufficient resection margin is not the absolute factor associated with the rate of survival and recurrence, although it is a key prognostic factor. The locoregional recurrence had no significant correlation with the distance of the PRM after curative gastrectomy.

Keywords: Gastric cancer, Proximal resection margin (PRM), Locoregional recurrence

\footnotetext{
* Correspondence: yongaaa5972@naver.com

'Department of Memorial Jin Pok Kim Gastric Cancer Center, Inje university

Paik Hospital, Inje University College of Medicine, 9, Mareunnae-ro, Jung-gu, Seoul 100-032, Korea

${ }^{2}$ Department of Surgery, Inje university Paik Hospital, Inje University College of Medicine, 9, Mareunnae-ro, Jung-gu, Seoul 100-032, Korea
} 


\section{Background}

Gastric cancer is the fourth most prevalent malignancy in Western countries, and its incidence is the highest in Korea [1,2]. It is widely accepted that surgery is the first line of therapy in patients with gastric cancer, for whom curative marginal resection is the only method for increasing the survival rate. Curative gastric cancer surgery basically includes stomach resection, lymph node dissection, and reconstruction. In patients with gastric cancer, surgical interventions are routinely performed considering both their conditions and cancer characteristics. To date, active studies have been conducted to identify prognostic factors in these patients. Thus, the pathologic condition after radical surgical resection has been established as the key prognostic factor. Both the lack of invasion of cancer cells at the resection margin and the appropriate dissection of surrounding lymph nodes are essential for obtaining successful treatment outcomes of curative resection [3].

It is mostly recommended that the resection margin be remote from the margin of the tumor for the prevention of its recurrence. In association with this, several studies have reported that the inadequate resection margin is related to locoregional recurrence [4-6]. Currently, however, there are no established guidelines for the distance of the resection margin; it is routinely subject to surgeons' technical expertise. The first part of the duodenum, 1 to $2 \mathrm{~cm}$ distal to the pylorus, is routinely used as the distal resection margin (DRM) in gastrectomy. However, the distance of the proximal resection margin (PRM) remains controversial, despite the fact that it is a key factor that is associated with the extent of gastrectomy.

We conducted this retrospective study to analyze the relationship between the distance of the PRM and the pattern of recurrence in patients with gastric cancer who underwent curative gastrectomy.

\section{Methods}

\section{Study population}

We performed surgical operations for a total of 896 patients with gastric adenocarcinoma at department of Memorial Jin Pok Kim, Korea Gastric Cancer Center, Inje Medical College, Seoul Paik Hospital, Seoul, Korea between September 2002 and December 2006. Of these, 122 patients were excluded because of other synchronous or metachronous cancers, positive surgical margins, or palliative treatment for gastric cancer. Therefore, 774 patients who were treated with curative gastrectomy were enrolled in the current study. Of these, 529 who underwent distal gastrectomy (29 underwent Billroth I surgery and 500 underwent Billroth II surgery) and 245 who underwent total gastrectomy. Thus, our clinical series of patients were classified into the distal gastrectomy group $(\mathrm{n}=529)$ and the total gastrectomy group $(\mathrm{n}=245)$. Types of surgical procedure were determined by the attending surgeon's preference, mainly based on the gastric cancer treatment guidelines of Japan [3].

Patients' clinical pathological data was collected from medical and computerized records. Based on pathologic examination, we retrospectively analyzed the clinical stage, $\mathrm{T}$ - and N-stage, tumor size, histologic type, Lauren's classification, venous, lymphatic, and neural invasion, tumor location, and the distance of the PRM. The distance of the PRM was defined as the distance extending from the proximal limit of the lesion to the site of the resection. It was not consistent with the intraoperative measurement. It was measured based on the results obtained from surgical specimens placed in $10 \%$ formalin solution for more than 12 hours. It was routinely evaluated using an intraoperative frozen section biopsy in all the patients. We analyzed the relationship between various clinicopathological factors and the recurrence, including the locoregional recurrence in particular.

The study population included patients who underwent radical gastrectomy with $\mathrm{D} 2$ lymphadenectomy. We made a diagnosis of cancer recurrence on physical examination, radiologic assessment, and endoscopy. Recurrences were classified as locoregional recurrence, hematogenous metastasis, peritoneal carcinomatosis, and multiple metastases. Main patterns of recurrence were recorded as the first site of detection at the time of diagnosis. By definition, the locoregional recurrences include local lymph node metastasis, extraluminal recurrence, recurrence within the gastric remnant stomach, and anastomotic recurrence after gastrectomy. The tumor stage was reported according to the sixth edition of the tumor-node-metastasis (TNM) classification of malignant tumor established by the International Union Against Cancer (UICC) [7]. Our clinical series of patients were followed up on until December 2011, with a mean follow-up period of 45 months (range: 1 to 111 months).

We obtained approval for this study from the Institutional Review Board at Inje university Paik Hospital. Written informed consent was obtained from patient for the publication of this report and any accompanying images.

\section{Statistical analysis}

Statistical analysis was done using SPSS version 12.0 for Windows (SPSS, Inc., Chicago, Illinois, United States). All data was expressed as mean \pm standard definition (SD). A $P$-value of $<0.05$ was considered to be statistically significant. Independent sample Student's t-tests were used to analyze the age, tumor size, and the distance of the PRM. In addition, the chi-squared test was used to analyze the differences in the above variables between the two groups. Furthermore, a log-rank test 
(univariate analysis) with the Kaplan-Meier method was used to analyze the disease-free survival (DFS) and the distance of the PRM. The Cox proportional hazards model and logistic regression tests were employed for multivariate analysis.

\section{Results}

Baseline and demographic data of the patients

In our series, there were 529 patients who underwent distal gastrectomy and 245 who underwent total gastrectomy. Thus, we classified our clinical series of patients into the distal gastrectomy group $(n=529)$ and the total gastrectomy group $(n=245)$. The mean age of the patients was 60 years (range: 24 to 88 years) in the distal gastrectomy group and 60 years (range: 24 to 87 years) in the total gastrectomy. The male-to-female ratio was 1.3:1.0 in the total gastrectomy group and 3.5:1.0 in the distal gastrectomy group. In both groups, sex and age had no significant correlation with the distance of the PRM, with the exception of age in the distal gastrectomy group. It is likely, early cancer is probably more, statistical significance was observed, that there is no clinical significance.

In both groups, the sex had no significant correlation with the distance of the PRM. But, age in the distal gastrectomy group was correlated with PRM diastnace. It is likely, early cancer is many subtota gastrectomy group, it was observed a statistically significant, but it seems not to be clinically significant.

The distance of the proximal resection margin in the total gastrectomy group

The mean distance of the PRM was $4.03 \mathrm{~cm}$ in the total gastrectomy group. That is, there were $68(27.8 \%), 73$ (29.8\%), and 104 (42.4\%) patients where the distance of the PRM was $<2 \mathrm{~cm}, 2$ to $4 \mathrm{~cm}$, and $>4 \mathrm{~cm}$, respectively. The distance of the PRM had a significant correlation with advanced T-stage $(P<0.001)$, advanced $\mathrm{N}$-stage $(P<0.001)$, vascular invasion $(P=0.007)$, lymphatic invasion $(P=0.003)$, neural invasion $(P<0.001)$, histological undifferentiation $(P=0.045)$, greater tumor size $(P<0.001)$, and the upper third of the tumor location $(P<0.001)$ (Table 1).

There were 81 patients who had a tumor recurrence; there were 16 cases of locoregional recurrence, 41 cases of peritoneal carcinomatosis, 11 cases of hematogenous metastasis, and 13 cases of multiple metastases. In addition, the recurrence was found to have a significant correlation with $\mathrm{T}$-stage $(P<0.001), \mathrm{N}$-stage $(P<0.001)$, PRM $(P=0.032)$, vascular invasion $(P<0.001)$, lymphatic invasion $(P<0.001)$, neural invasion $(P<0.001)$, histology $(P=0.004)$, Lauren's classification $(P=0.006)$, tumor size $(P<0.001)$, and tumor location $(P<0.001)$ (Table 2$)$. Multivariate analysis performed by applying logistic
Table 1 Clinicopathological factors depending on the distance of the proximal resection margin (PRM) in the patients who underwent curative total gastrectomy

\begin{tabular}{|c|c|c|c|c|c|}
\hline \multirow[t]{2}{*}{ Parameter } & \multicolumn{3}{|c|}{ PRM (cm) } & & \multirow[t]{2}{*}{$P$ value } \\
\hline & $\leq 2$ & $2-4$ & $\geq 4$ & & \\
\hline Gender & & & & & 0.305 \\
\hline Male & 35 & 42 & 62 & 139 & \\
\hline Female & 33 & 31 & 42 & 106 & \\
\hline Age (years) & & & & & 0.403 \\
\hline$\leq 60$ & 28 & 35 & 50 & 113 & \\
\hline$>60$ & 40 & 38 & 54 & 132 & \\
\hline T-stage & & & & & $<0.001$ \\
\hline $\mathrm{T} 1$ & 2 & 21 & 36 & 59 & \\
\hline $\mathrm{T} 2$ & 24 & 17 & 37 & 78 & \\
\hline $\mathrm{T} 3$ & 40 & 28 & 29 & 97 & \\
\hline T4 & 2 & 7 & 2 & 11 & \\
\hline $\mathrm{N}$-stage & & & & & $<0.001$ \\
\hline No & 11 & 27 & 52 & 90 & \\
\hline N1 & 14 & 19 & 23 & 56 & \\
\hline N2 & 13 & 8 & 10 & 31 & \\
\hline N3 & 30 & 19 & 19 & 68 & \\
\hline Vascular invasion & & & & & 0.007 \\
\hline Absent & 37 & 54 & 78 & 169 & \\
\hline Present & 31 & 19 & 26 & 76 & \\
\hline Lymphatic invasion & & & & & 0.003 \\
\hline Absent & 7 & 23 & 33 & 63 & \\
\hline Present & 31 & 19 & 71 & 182 & \\
\hline Neural invasion & & & & & $<0.001$ \\
\hline Absent & 6 & 28 & 37 & 71 & \\
\hline Present & 62 & 45 & 67 & 174 & \\
\hline Histology & & & & & 0.045 \\
\hline Differentiated & 13 & 18 & 34 & 65 & \\
\hline Undifferentiated & 55 & 55 & 70 & 180 & \\
\hline Lauren's classification & & & & & 0.316 \\
\hline Intestinal & 9 & 16 & 28 & 53 & \\
\hline Diffuse & 43 & 42 & 49 & 134 & \\
\hline Mixed & 16 & 15 & 27 & 58 & \\
\hline Tumor size $(\mathrm{cm})$ & & & & & $<0.001$ \\
\hline$\leq 2$ & 0 & 6 & 13 & 19 & \\
\hline $2-5$ & 8 & 26 & 43 & 77 & \\
\hline$>5$ & 60 & 41 & 48 & 149 & \\
\hline Tumor location & & & & & $<0.001$ \\
\hline Lower third & 0 & 1 & 13 & 14 & \\
\hline Middle third & 13 & 34 & 73 & 120 & \\
\hline Upper third & 34 & 31 & 18 & 83 & \\
\hline Entire & 21 & 7 & 0 & 28 & \\
\hline
\end{tabular}


Table 2 Correlations with clinicopathological factors, recurrence, and locoregional recurrence in the patients who underwent curative total gastrectomy

\begin{tabular}{|c|c|c|c|c|c|}
\hline \multirow[t]{2}{*}{ Parameter } & \multicolumn{2}{|c|}{ Recurrence } & \multirow[t]{2}{*}{$P$ value } & \multicolumn{2}{|c|}{ Locoregional recurrence } \\
\hline & Negative & $\overline{\text { Positive }}$ & & Negative & Posit \\
\hline Gender & & & 0.592 & & \\
\hline Male & 95 & 44 & & 29 & 15 \\
\hline Female & 69 & 37 & & 36 & 1 \\
\hline Age (years) & & & 0.655 & & \\
\hline$\leq 60$ & 74 & 39 & & 31 & 8 \\
\hline$>60$ & 90 & 42 & & 34 & 8 \\
\hline T-stage & & & $<0.001$ & & \\
\hline $\mathrm{T} 1$ & 59 & 0 & & 0 & 0 \\
\hline $\mathrm{T} 2$ & 62 & 16 & & 13 & 3 \\
\hline $\mathrm{T} 3$ & 39 & 58 & & 46 & 12 \\
\hline $\mathrm{T} 4$ & 4 & 7 & & 6 & 1 \\
\hline $\mathrm{N}$-stage & & & $<0.001$ & & \\
\hline NO & 83 & 7 & & 7 & 0 \\
\hline N1 & 42 & 14 & & 7 & 7 \\
\hline N2 & 13 & 18 & & 15 & 3 \\
\hline N3 & 26 & 42 & & 36 & 6 \\
\hline
\end{tabular}

Vascular invasion

$<0.001$

Absent

Present

Lymphatic invasion

$<0.001$

Present

Neural invasion

Absent

$<0.001$

Present

Histology

Differentiated

0.004

Undifferentiated

Lauren's classification

Diffuse

Proximal resection margin $(\mathrm{cm})$

0.032

$\begin{array}{ll}37 & 31 \\ 51 & 22 \\ 76 & 28\end{array}$

$\geq 4$

Tumor size (cm)

$<0.001$

$\leq 2$

$2-5$

19 
Table 2 Correlations with clinicopathological factors, recurrence, and locoregional recurrence in the patients who underwent curative total gastrectomy (Continued)

\begin{tabular}{lcccc}
\hline Tumor location & & & & 0.122 \\
Lower third & 7 & 7 & 4 & 3 \\
Middle third & 83 & 19 & 13 & 5 \\
Upper third & 64 & 18 & 16 & 6 \\
Entire & 10 & 18 & & 2 \\
\hline
\end{tabular}

regression showed only a significant correlation with N-stage $(P<0.023)$.

On univariate analysis, the pattern of recurrence had a significant correlation with locoregional recurrence after curative resection; these include gender $(P<0.001), \mathrm{N}$ stage $(P=0.013)$ and Lauren's classification $(P<0.021)$ (Table 2). Multivariate analysis showed that the N-stage was the only independent prognostic variable associated with the locoregional recurrence $(P=0.039)$. The risk of locoregional recurrence in patients with N3 was 2.677fold higher than that in patients with other $\mathrm{N}$-stages (hazard ratio: 3.484 ; 95\% CI: 1.053 to 6.805 ).

On univariate analysis based on the Kaplan-Meier method, the cumulative DFS was significantly shorter in the patients with a shorter distance of the PRM as compared with those with a longer distance of the PRM $(P=0.019)$ (Figure 1). However, there was no significant correlation between the cumulative locoregional recurrence and the PRM $(P=0.565)$. Ultimately, while the PRM distance in total gastrectomy influenced the DFS, it had no effect on the locoregional recurrence.

The mean distance of the PRM was $6.4 \mathrm{~cm}$ in the distal gastrectomy group. That is, there were 71 (13.4\%), 187 (35.3\%), and 271 (51.2\%) patients where the distance of the PRM was $<3 \mathrm{~cm}, 3$ to $6 \mathrm{~cm}$, and $>6 \mathrm{~cm}$, respectively.

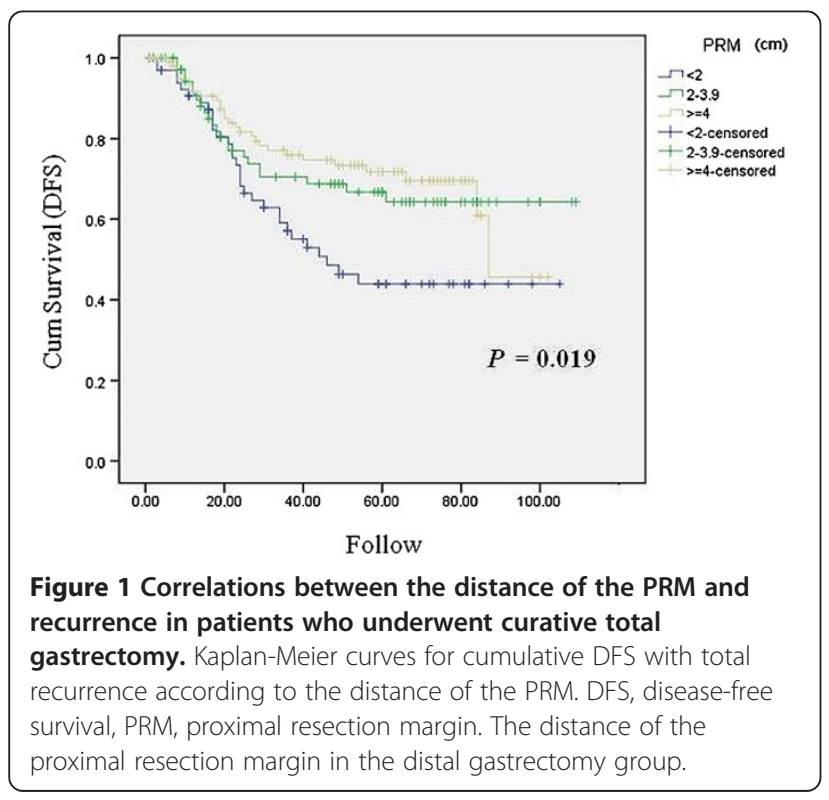

The distance of the PRM had a significant correlation with advanced T-stage $(P<0.001)$, advanced N-stage $(P<0.001)$, younger age $(P=0.044)$, vascular invasion $(P=0.013)$, histological undifferentiation $(P<0.001)$, greater tumor size $(P<0.001)$, and the middle third of the tumor location $(P<0.001)$ (Table 3$)$.

There were 73 patients who had a tumor recurrence; there were 26 cases of locoregional recurrence, 19 cases of peritoneal carcinomatosis, 17 cases of hematogenous metastasis, and 11 cases of multiple metastases. In addition, the recurrence had a significant correlation with T-stage $(P<0.001), \mathrm{N}$-stage $(P<0.001)$, vascular invasion $(P<0.001)$, lymphatic invasion $(P<0.001)$, neural invasion $(P<0.001)$, tumor size $(P<0.001)$, and tumor location $(P=0.003)$ (Table 4$)$. Multivariate analysis performed by applying logistic regression showed that the recurrence had a significant correlation with $\mathrm{N}$-stage $(P<0.001)$, vascular invasion $(P=0.009)$, and the lower third of tumor location $(P=0.035)$. On univariate analysis, the pattern of recurrence had no significant correlation with locoregional recurrence after curative resection (Table 4). Multivariate analysis showed that the T-stage was the only independent prognostic variable associated with the locoregional recurrence $(P=0.021)$; the risk of locoregional recurrence in T3-stage patients was 16.308fold higher than that in patients with other T-stage classifications (hazard ratio: 3.484; 95\% CI: 1.535 to 173.245 ).

On univariate analysis using the Kaplan-Meier method, the cumulative DFS had no significant correlation with the distance of the PRM $(P=0.089)$ (Figure 2). Also, there was no significant correlation between the cumulative locoregional recurrence and the PRM $(P=0.584)$.

\section{Discussion}

In the past, total gastrectomy was considered as a standard modality in patients with gastric cancer because it could safely assure marginal distance [8,9]. However, there were no significant differences in the survival rate and complications between the subtotal and total gastrectomy in patients where the gastric cancer occurred in the distal third of the stomach [8]. For successful curative gastrectomy, obtaining appropriate resection margin is crucial. The resection margin is determined according to the degree of progression, pathologic findings, location of cancer, and the chance of metastasis to 
Table 3 Clinicopathological factors depending on the distance of the proximal resection margin (PRM) in the patients who underwent curative distal gastrectomy

\begin{tabular}{|c|c|c|c|c|c|}
\hline \multirow[t]{2}{*}{ Parameter } & \multicolumn{3}{|c|}{ PRM (cm) } & & \multirow[t]{2}{*}{$P$ value } \\
\hline & $\leq 3$ & $3-6$ & $\geq 6$ & & \\
\hline Gender & & & & & 0.936 \\
\hline Male & 47 & 138 & 189 & 374 & \\
\hline Female & 24 & 49 & 82 & 106 & \\
\hline Age (years) & & & & & 0.044 \\
\hline$\leq 60$ & 42 & 86 & 119 & 247 & \\
\hline$>60$ & 29 & 101 & 152 & 282 & \\
\hline T-stage & & & & & $<0.001$ \\
\hline $\mathrm{T} 1$ & 29 & 97 & 181 & 307 & \\
\hline $\mathrm{T} 2$ & 23 & 47 & 65 & 135 & \\
\hline T3 & 18 & 42 & 24 & 84 & \\
\hline T4 & 1 & 1 & 1 & 3 & \\
\hline N-stage & & & & & $<0.001$ \\
\hline No & 37 & 106 & 187 & 330 & \\
\hline $\mathrm{N} 1$ & 14 & 42 & 60 & 116 & \\
\hline N2 & 9 & 22 & 18 & 49 & \\
\hline N3 & 11 & 17 & 6 & 34 & \\
\hline Vascular invasion & & & & & 0.013 \\
\hline Absent & 59 & 158 & 248 & 465 & \\
\hline Present & 12 & 29 & 23 & 64 & \\
\hline Lymphatic invasion & & & & & 0.057 \\
\hline Absent & 29 & 90 & 144 & 263 & \\
\hline Present & 42 & 97 & 127 & 266 & \\
\hline Neural invasion & & & & & 0.062 \\
\hline Absent & 39 & 108 & 176 & 323 & \\
\hline Present & 32 & 79 & 95 & 206 & \\
\hline Histology & & & & & $<0.001$ \\
\hline Differentiated & 20 & 67 & 146 & 233 & \\
\hline Undifferentiated & 51 & 120 & 125 & 296 & \\
\hline Lauren's classification & & & & & 0.199 \\
\hline Intestinal & 24 & 66 & 127 & 217 & \\
\hline Diffuse & 33 & 81 & 81 & 195 & \\
\hline Mixed & 14 & 40 & 63 & 117 & \\
\hline Tumor size $(\mathrm{cm})$ & & & & & $<0.001$ \\
\hline$\leq 3$ & 25 & 68 & 151 & 244 & \\
\hline $3-5$ & 14 & 46 & 60 & 120 & \\
\hline$\geq 5$ & 32 & 73 & 60 & 165 & \\
\hline Tumor location & & & & & $<0.001$ \\
\hline Lower third & 33 & 87 & 217 & 337 & \\
\hline Middle third & 38 & 100 & 54 & 192 & \\
\hline
\end{tabular}

lymph node. The distal margin of resection is usually 1 to $2 \mathrm{~cm}$ away from the pylorus, the first part of duodenum. In contrast, the distance of the PRM for gastrectomy remains controversial. It is mostly recommended, however, that the distance of the PRM be set. This is because a positive margin is an independent unfavorable factor for patients who undergo gastrectomy.

According to Bozzetti et al. [4], the distance of the PRM should be maintained at $3 \mathrm{~cm}$ in patients with gastric cancer without serosal invasion, and $>6 \mathrm{~cm}$ in those with serosal invasion, or those for whom an accurate assessment is not possible. According to this study, the most important factor affecting cancer infiltration at resection margin is the primary tumor depth of the gastric wall. It is statistically significant, regardless of cancer location, size, gross findings, pathologic findings, and lymph node positivity. According to the Japanese Gastric Cancer Association (JGCA) guidelines, the distance of the PRM should be $1 \mathrm{~cm}$ in patients with mucosal invasion, $3 \mathrm{~cm}$ in those with well-differentiated muscle layer and serosa, and $>5 \mathrm{~cm}$ in those with histological undifferentiation and serosal invasion [3]. Further, another report stated that the length of cancer invasion along the gastric wall was several millimeters at the margin of cancer lesion on gross findings in patients with intestinal type gastric cancer, and several centimeters in those with diffuse type gastric cancer [5]. Consistent with this, Gall and Hermanek [10] reported that the length of cancer invasion was $>8 \mathrm{~cm}$ in patients with diffuse type gastric cancer and $>4 \mathrm{~cm}$ in patients with intestinal type gastric cancer. Moreover, Ha and Kwon [5] reported that the survival rate was significantly higher in patients with advanced gastric cancer located in the distal third who had a $>3-\mathrm{cm}$ resection margin. In the current study, however, there was no significant difference in survival rate between patients with advanced gastric cancer located in the middle third and proximal third who had a $>3-\mathrm{cm}$ resection margin, and those who had a $<3-\mathrm{cm}$ resection margin. Moreover, our results also showed that the distance of the PRM had a significant correlation with the advanced $\mathrm{T}$-stage, advanced $\mathrm{N}$-stage, vascular invasion, lymphatic invasion, neural invasion, histological undifferentiation, greater tumor size, and the upper third of tumor location in patients who underwent total gastrectomy. However, the recurrence had a significant correlation with $\mathrm{N}$-stage only. The distance of the PRM had a significant correlation with advanced T-stage, advanced $\mathrm{N}$-stage, vascular invasion, lymphatic invasion, neural invasion, histological undifferentiation, greater tumor size, and the middle third of tumor location in patients who underwent distal gastrectomy. However, the recurrence had a significant correlation with $\mathrm{N}$-stage, vascular invasion, and the lower third of tumor location. 
Table 4 Correlations with clinicopathological factors, recurrence, and locoregional recurrence in the patients who underwent curative distal gastrectomy

\begin{tabular}{|c|c|c|c|c|c|c|}
\hline \multirow[t]{2}{*}{ Parameter } & \multicolumn{2}{|c|}{ Recurrence } & \multirow[t]{2}{*}{$P$ value } & \multicolumn{2}{|c|}{ Locoregional recurrence } & \multirow[t]{2}{*}{$P$ value } \\
\hline & Negative & Positive & & Negative & Positive & \\
\hline Gender & & & 0.348 & & & 0.172 \\
\hline Male & 319 & 55 & & 33 & 22 & \\
\hline Female & 137 & 18 & & 14 & 4 & \\
\hline Age (years) & & & 0.302 & & & 0.100 \\
\hline$\leq 60$ & 217 & 30 & & 16 & 14 & \\
\hline$>60$ & 239 & 43 & & 31 & 12 & \\
\hline T-stage & & & $<0.001$ & & & 0.599 \\
\hline T1 & 301 & 6 & & 3 & 3 & \\
\hline $\mathrm{T} 2$ & 111 & 24 & & 14 & 10 & \\
\hline T3 & 42 & 42 & & 29 & 13 & \\
\hline T4 & 2 & 1 & & 1 & 0 & \\
\hline $\mathrm{N}$-stage & & & $<0.001$ & & & 0.555 \\
\hline NO & 326 & 4 & & 2 & 2 & \\
\hline N1 & 95 & 21 & & 14 & 7 & \\
\hline N2 & 26 & 23 & & 17 & 6 & \\
\hline N3 & 9 & 25 & & 14 & 11 & \\
\hline Vascular invasion & & & $<0.001$ & & & 0.957 \\
\hline Absent & 426 & 39 & & 25 & 14 & \\
\hline Present & 30 & 34 & & 22 & 12 & \\
\hline Lymphatic invasion & & & $<0.001$ & & & 0.682 \\
\hline Absent & 256 & 7 & & 5 & 2 & \\
\hline Present & 200 & 66 & & 42 & 24 & \\
\hline Neural invasion & & & $<0.001$ & & & 0.975 \\
\hline Absent & 306 & 17 & & 11 & 6 & \\
\hline Present & 150 & 56 & & 36 & 20 & \\
\hline Histology & & & 0.118 & & & 0.520 \\
\hline Differentiated & 207 & 26 & & 18 & 8 & \\
\hline Undifferentiated & 249 & 47 & & 29 & 18 & \\
\hline Lauren's classification & & & 0.356 & & & 0.275 \\
\hline Intestinal & 192 & 25 & & 18 & 7 & \\
\hline Diffuse & 167 & 28 & & 19 & 9 & \\
\hline Mixed & 97 & 20 & & 10 & 10 & \\
\hline Proximal resection margin $(\mathrm{cm})$ & & & 0.054 & & & 0.275 \\
\hline$\leq 3$ & 55 & 16 & & 10 & 6 & \\
\hline $3-6$ & 161 & 26 & & 14 & 12 & \\
\hline$\geq 6$ & 240 & 31 & & 23 & 8 & \\
\hline Tumor size $(\mathrm{cm})$ & & & $<0.001$ & & & 0.862 \\
\hline$\leq 3$ & 240 & 4 & & 3 & 1 & \\
\hline $3-5$ & 102 & 18 & & 12 & 6 & \\
\hline$\geq 5$ & 114 & 51 & & 32 & 19 & \\
\hline Location & & & 0.003 & & & 0.108 \\
\hline Lower third & 279 & 58 & & 40 & 18 & \\
\hline Middle third & 177 & 15 & & 7 & 8 & \\
\hline
\end{tabular}




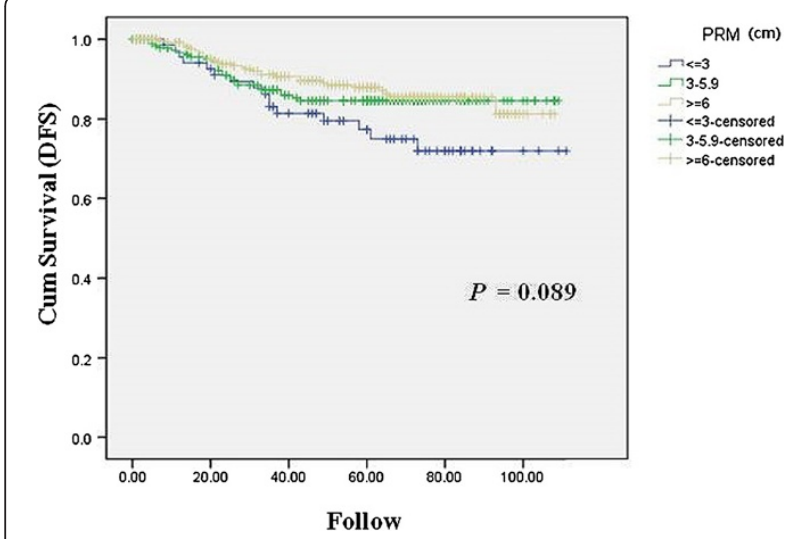

Figure 2 Correlations between the distance of the PRM and recurrence in the patients who underwent curative distal gastrectomy. Kaplan-Meier curves for cumulative DFS with total recurrence according to the distance of the PRM. DFS, disease-free survival, PRM, proximal resection margin.

It is generally known that there are three major patterns of recurrence in patients with gastric cancer undergoing curative surgery; these include locoregional recurrence, peritoneal dissemination, and distant metastasis. The locoregional recurrence is the most common in Western countries, but is rare in Asian countries $[11,12]$. From this context, Sasako et al. [13] confirmed that peritoneal dissemination was the main recurrence type of gastric cancer after curative gastrectomy with an extended lymphadenectomy according to the JCOG (Japan Clinical Oncology Group) study 9501. In the current study, we found that peritoneal dissemination was the most common, followed by the multiple recurrences in the patients who underwent total gastrectomy. In the patients who underwent distal gastrectomy, however, locoregional recurrence was the most common, followed by peritoneal dissemination.

Deng et al. [14] analyzed 169 cases of recurrence in patients with gastric cancer who were treated with curative resection, reporting that there was a significant correlation between the locoregional recurrence and Lauren's classification. Moreover, Yoo et al. [15] analyzed 508 cases of recurrence in patients with gastric cancer who were treated with potentially curative gastrectomy, reporting that $33 \%$ of total recurrences involved the locoregional site. These authors also noted that the locoregional recurrence had a significant correlation with older age, large tumor size, diffuse type, and proximal location. According to other studies, there are clinicopathologic factors with a predictive value for the locoregional recurrence and these include the proximal location, older age, male sex, advanced stage (T3 to 4, and Nodal metastasis), infiltrative growth, diffuse type, and stromal resection [12,16,17]. In our clinical series of patients, on univariate analysis, the male sex, N-stage, and Lauren's classification had a significant correlation with the locoregional recurrence after curative total gastrectomy. On multivariate analysis, however, the N-stage was the only independent prognostic factor that was found to be associated with the locoregional recurrence. In patients who underwent curative distal gastrectomy, however, no significant correlation with locoregional recurrence was found on either univariate or multivariate analysis.

It is generally recommended that the length of resection margin be sufficient for lowering the chance of local recurrence, but this does not apply to all cases. Papachristou and Fortner argued that at least a $6.5-\mathrm{cm}$ resection margin should be maintained to prevent local recurrence [6]. In addition, Nakamura et al. [18] insisted that cancer invasion at the resection margin is not frequent and meaningless in patients with early gastric cancer, although it is a key prognostic factor. Consistent with this, Kim et al. [19] reported that the distance of the PRM had no negative effects on the prognosis of patients with early gastric cancer. According to these authors, there was a close relationship between the distance of the PRM and the prognosis in patients with advanced gastric cancer, but they contradicted the relationship between the distance of the PRM and locoregional recurrence. Our results show that there was no significant correlation between the locoregional recurrence and the distance of the PRM.

\section{Conclusions}

In conclusion, our results indicate that a sufficient resection margin is not the absolute factor associated with the rate of survival and recurrence, although it is a key prognostic factor. The locoregional recurrence had no significant correlation with the distance of the PRM after curative gastrectomy. The distance of the PRM observed in the operative field or the range of palpation is important, but it should be carefully evaluated as microscopic tumor may be present depending on the characteristics of the tumor. It would therefore be mandatory to intraoperatively perform a frozen section biopsy of the PRM. In addition, it is also necessary to avoid excessive resection in patients who are negative for an intraoperative frozen section biopsy of the PRM, which is essential for improving the quality of life and minimizing the occurrence of complications in patients undergoing curative gastrectomy.

\section{Abbreviations}

DFS: Disease free survival; DRM: Distal resection margin; PRM: Proximal resection margin; TNM: Tumor-node-metastasis; UICC: Union for International Cancer Control.

\section{Competing interests}

The authors declare that they have no competing interests. 


\section{Authors' contributions}

HJ designed this study, collected data, performed analysis. WY also designed the study, performed analysis, and drafted the manuscript. SW, YG and BM participated in the study, literature search, and study coordination. All

authors read and approved the final manuscript.

Received: 9 March 2014 Accepted: 8 September 2014

Published: 23 September 2014

\section{References}

1. Korean Gastric Cancer Association: Nationwide gastric cancer report in Korea. J Korean Gastric Cancer Assoc 2002, 2:105-114.

2. Ferlay J, Bray F, Pisani P, Parkin DM: GLOBOCAN 2002: Cancer Incidence, Mortality And Prevalence Worldwide. Lyon: IARC Press; 2004.

3. Nakajima T: Gastric cancer treatment guidelines in Japan. Gastric Cancer 2002, 5:1-5.

4. Bozzetti F, Bonfanti G, Bufalino R, Menotti V, Persano S, Andreola S, Doci R, Gennari L: Adequacy of margins of resection in gastrectomy for cancer. Ann Surg 1982, 196:682-690.

5. Ha TK, Kwon SJ: Clinical importance of the resection margin distance in gastric cancer patients. J Korean Gastric Cancer Assoc 2006, 6:277-283.

6. Papachristou DN, Fortner JG: Local recurrence of gastric adenocarcinomas after gastrectomy. J Surg Oncol 1981, 18:47-53.

7. Hermanek P: Surgical pathology-the TNM system. Langen-becks Arch Chir 1982, 358:57-63.

8. Gouzi JL, Huquier M, Fagniez PL, Launois B, Flamant Y, Lacaine F, Paquet JC, Hay JM: Total versus subtotal gastrectomy for adenocarcinoma of ther gastric antrum. A French prospective controlled study. Ann Surg 1989, 209:162-166.

9. Bozzetti F, Marubini E, Bonfanti G, Miceli R, Piano C, Gennari L, The Italian Gastrointestinal Tumor Study Group: Subtotal versus total gastrectomy for gastric cancer. Ann Surg 1999, 230:170-178.

10. Gall FP, Hermanek P: New aspects in the surgical treatment of gastric carcinoma-a comparative study of 1,636 patients operated on between 1969 and 1982. Eur J Surg Oncol 1985, 11:219-225.

11. Roviello F, Marrelli D, de Manzoni G, Morqaqni P, Saraqoni L, De Stefano A: Prospective study of peritoneal recurrence after curative surgery for gastric cancer. Br J Surg 2003, 90:1113-1119.

12. Maehara Y, Hasuda S, Koga T, Tokunaga E, Kakeji Y, Sugimachi K Postoperative outcome and sites of recurrence in patients of following curative resection of gastric cancer. Br J Surg 2000, 87:353-357.

13. Sasako M, Sano T, Yamamoto S, Kurokawa Y, Nashimoto A, Kurita A, Hiratsuka M, Tsujinaka T, Kinoshita T, Arai K, Yamamura Y, Okajima K: D2 lymphadenectomy alone or with para-aortic nodal dissection for gastric cancer. N Engl J Med 2008, 359:453-462.

14. Deng JG, Liang H, Wang DC, Sun D, Pan Y, Liu Y: Investigation of the recurrence patterns of gastric cancer following a curative resection. Surg Today 2011, 41:210-215.

15. Yoo CH, Noh SH, Shin DW, Choi SH, Min JS: Recurrence following curative resection for gastric carcinoma. Br J Surg 2000, 87:236-242.

16. Wu CW, Lo SS, Shen KH, Hsieh MC, Chen JH, Chiang JH, Lin HJ, Li AY, Lui WY: Incidence and factors associated with recurrence patterns after intended curative surgery for gastric cancer. World J Surg 2003, 27:153-158.

17. Schwarz RE, Zagala-Nevarez K: Recurrence patterns after radical gastrectomy for gastric cancer: prognostic factors and implications for postoperative adjuvant therapy. Ann Surg Oncol 2002, 9:394-400

18. Nakamura K, Ueyama T, Yao T, Xuan ZX, Ambe K, Adachi Y, Yakeishi Y, Matsukuma A, Enjoji M: Pathology and prognosis of gastric carcinoma: findings in 10,000 patients who underwent primary gastrectomy. Cancer 1992, 70:1030-1037.

19. Kim SH, Karpeh MS, Klimstra DS, Leung D, Brennan MF: Effect of microscopic resection line disease on gastric cancer survival. J Gastrointest Surg 1999, 3:24-33.

doi:10.1186/1477-7819-12-296

Cite this article as: Ohe et al.: Prognostic value of the distance of proximal resection margin in patients who have undergone curative gastric cancer surgery. World Journal of Surgical Oncology 2014 12:296.

\section{Submit your next manuscript to BioMed Central and take full advantage of:}

- Convenient online submission

- Thorough peer review

- No space constraints or color figure charges

- Immediate publication on acceptance

- Inclusion in PubMed, CAS, Scopus and Google Scholar

- Research which is freely available for redistribution 